\title{
INHERITANCE OF LEAF SHAPE IN FLUE-CURED TOBACCO (NICOTIANA TABACUM L.)*
}

\author{
A. B. HUMPHREY, D. F. MATZINGER and T. J. MANN \\ Departments of Genetics and Crop Science, North Carolina State of U.N.C., \\ Raleigh, North Carolina
}

Received I5.iv.64

\section{INTRODUCTION}

Clausen and Cameron (i 944 ) reported the effects of three pairs of alleles on leaf shape in tobacco. $\mathrm{Pt}$, petioled, produced a narrow, petioled leaf as contrasted to normal, pt. Pd, petioled, resembled $\mathrm{Pt}$ in effect, but to a lesser degree. Br, broad, had a broad leaf base as contrasted to a constricted leaf base of the standard, br. For each of these characters the heterozygote was approximately intermediate between the two homozygotes, although it was sometimes difficult to distinguish the heterozygote from one of the homozygotes.

Van der Veen (1957) studied the effects of these same three allelic pairs and determined their influence on the inheritance of leaf shape in the $F_{1}, F_{2}, F_{3}$ and backcross generations among four varieties. The pure lines which he studied, together with their leaf type genotypes are:-

$\begin{array}{ll}\text { Hongaars Gartenblatt (HG) } & \text { ptptpdpdbrbr } \\ \text { Atropurpurea (Atr) } & \text { ptptpdpdbrbr } \\ \text { Amersfoorter (Am) } & \text { PtPtpdpdBrBr } \\ \text { Keurhorst Elite (KE) } & \text { ptptPdPdBrBr }\end{array}$

In most cases the $F_{1}$ hybrids were intermediate between their parents. The Pd and Pt loci seemed to affect the same characters, but the effect of $\mathrm{Pt}$ was about twice that of Pd. Since the genetic background of the crosses was quite diverse, stratification of the material according to leaf number was helpful in classification.

In a later study Van der Veen and Bink ( 1961 ) compared the effects of $\mathrm{Pt}$ and $\mathrm{Br}$ in a cross similar to HG-Am, except that the material was in a homogeneous genetic background and of pdpd genetic constitution. Various measurement criteria indicated that Pt affected leaf width, angle of venation, petiole (wing) width, length of petiole, number of leaves, rate of leaf production during early growth and internode length.

Visual observations of flue-cured tobacco varieties grown in the United States suggest that basic leaf shape may be controlled by only a few genes. These would then be the $\mathrm{Pt}, \mathrm{Pd}$ and $\mathrm{Br}$ loci mentioned

* Published with the approval of the Director of Research as Paper No: 1746 of the Journal Series of the North Carolina Agricultural Experiment Station. This investigation was supported in part by NIH Grant GMI 1546. 
above. Since most varieties have a broad leaf base, they are probably of genotype $\mathrm{BrBr}$. The major source of variation in leaf shape must then be due to the effects of the Pt and Pd loci. Because of the environmental influence on the expression of these genes it is not possible to assess visually the specific genotype of each variety. This study was initiated to investigate the mode of inheritance of basic leaf shape in a cross of two varieties and to develop measurement criteria to distinguish among genotypes.

\section{RESULTS OF PRELIMINARY EXPERIMENTS AND DERIVATION OF STOCKS}

In advanced generations of a cross between two flue-cured tobacco varieties, unidirectional transgressive segregation for shape of leaves was observed. These commercial varieties, then widely grown, were Hicks Broadleaf (Hicks) and Coker 139 ( $\mathrm{C}_{139}$ ). In addition to other

TABLE I

Pedigree and leaf type of source material

\begin{tabular}{|c|c|}
\hline Pedigree & Leaf type \\
\hline I8-8 & I \\
$06-6$ & II \\
$14-5$ & II \\
$18-2$ & II \\
$05-8$ & III \\
\hline
\end{tabular}

morphological features, they differ in leaf width. In spite of its name, Hicks produces narrower leaves than $\mathrm{C}_{1} 39$. The width of the leaves of $F_{1}$ plants was similar to that of the narrow-leaved parent suggesting at least partial dominance of genes for narrow leaves.

In the $F_{2}$ generation individual plants produced leaves ranging in width from that of the $\mathrm{C}_{1} 39$ parent to those decidedly narrower than Hicks. Among the $F_{3}$ families, each resulting from selfing individual $\mathrm{F}_{2}$ plants, uniform rows of plants of the transgressive narrow leaf type were found. A visual scoring system was assigned where I indicated plants with leaves narrower than Hicks, II for plants similar to Hicks and the $F_{1}$ and III for plants with leaves as broad as $\mathrm{C}_{139}$.

Five progeny rows which bred true in the $F_{3}$ generation were chosen for further study. The pedigree and leaf type of each is shown in table $\mathrm{I}$.

Crosses among these selections and crosses of each to Hicks, Gi 39 and the $\mathrm{F}_{1}$ were made in 1958 . Two replications of this material were grown in 1959. Also included for a check on the visual scoring were the five recovered lines, Hicks, $\mathrm{C}_{139}, \mathrm{~F}_{1}$ and the backcrosses of $\mathrm{F}_{1}$ to Hicks and Gr39.

All of the recovered lines, Hicks, $\mathrm{C}_{1} 39$ and $\mathrm{F}_{1}$ were given the same 
scores as in the previous test. Intercrosses among the three recovered II lines and crosses of each to Hicks were uniform II, indicating that the three recovered II types were of the same genotype as Hicks. Crosses of all recovered II types to $\mathrm{G}_{\mathrm{I}} 39$ were uniform II, and similar to the $F_{1}$. The recovered $\mathrm{I}$, when crossed to $\mathrm{C}_{139}$, was classified as II and when crossed to the $\mathrm{F}_{1}$ segregated I and II. The recovered III crossed to Gi 39 was also uniform III.

Direct evidence for more than one locus came from several crosses. The backcross of the $F_{1}$ to Hicks segregated but did not give the extreme phenotypes, whereas, the backcross to $\mathrm{C}_{1} 39$ and the cross of $F_{1}$ to the recovered III segregated II and III. The appearance of two new phenotypic classes was also evident. When i 8-8 was crossed to each recovered II and Hicks all rows were uniform, but were intermediate between I and II. This class was designated I'. Likewise, the cross of $05-8 \times$ Hicks yielded a uniform intermediate between II and III, designated II'. It was hypothesised that two loci were involved. A genotypic model was proposed as follows:-

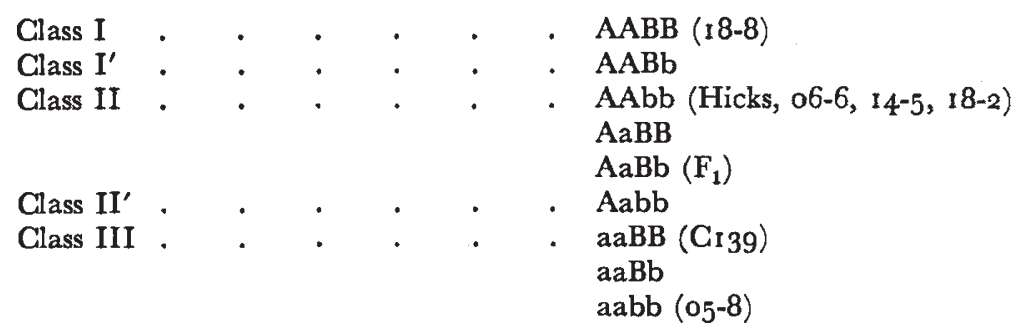

In 1960, additional crosses were made for further verification of this two-locus genotypic model. The progeny were evaluated in two replications in 196I. Within a row of $F_{1} \times 14-5$ in the 1960 nursery, four genotypes were expected: $\mathrm{AABb}\left(\mathrm{I}^{\prime}\right), \mathrm{AAbb}$ (II), $\mathrm{AaBb}$ (II) and $\mathrm{Aabb}\left(\mathbf{I I}^{\prime}\right)$. Individual plants from this segregating row were selfpollinated. The narrowest plants were chosen to verify that these narrow plants were not $\mathrm{AABB}(\mathrm{I})$ but $\mathrm{AABb}\left(\mathrm{I}^{\prime}\right)$. The broadest plants were chosen to verify that these were not plants of phenotypic Class III. In addition some plants representing the mean of the row were chosen. The self-progeny from the plants were scored in $196 r$ as shown in table 2.

Similarly, plants were scored and self-progeny evaluated from the cross of $F_{1}$ to Hicks. This cross has the same expectation as the previous cross. All progenies verified the parental type. Thus, from these two crosses, no progenies could be obtained which bred true for phenotypic classes I or III. Both stable II and rows showing segregation for the complete range were obtained from plants of intermediate phenotypes as expected.

Also in $196 \mathrm{I}$, verification was made of the two new classes, $I^{\prime}$ and $\mathrm{II}^{\prime}$. The $\mathrm{I}^{\prime}$ families arising from Hicks $\times 18-8$ and $\mathrm{I} 4-5 \times 18-8$ were self-pollinated and yielded plants of three classes: I, I' and II. When 
these type $I^{\prime}$ families were crossed to Hicks or the recovered II, I4-5, only progenies of types I' and II were observed. The hypothesised genotype, $\mathrm{AABb}$, fits these observations. When the $\mathrm{II}^{\prime}$ family arising from Hicks $\times 05^{-8}$ was self-pollinated it produced plants of three classes: II, II' and III. When crossed to Hicks or recovered type II, I4-5, only plants of types II' and III were observed. Thus, the proposed classification of Aabb for this family was verified.

Verification that 05-8 was a different genotype than $\mathrm{C}_{13} 39$, although both were previously scored III phenotypically, was ascertained from two test crosses. The type III, $\left(\mathrm{G}_{139} \times 05-8\right) \mathbf{F}_{1}$ was crossed to Hicks. Resulting plants of both II and $\mathrm{II}^{\prime}$ indicated that $05-8$ was in fact aabb. In all previous cases, the three genotypes with aa-- were scored

TABLE 2

Progeny test of selected phenotypic classes

\begin{tabular}{|c|l|l|}
\hline $\begin{array}{c}\text { Parent plant } \\
\text { phenotypes }\end{array}$ & Progeny phenotypes & \multicolumn{1}{|c|}{ Verification of genotypes } \\
\hline$I^{\prime}$ & I, I', II & Verifies parent plant (AABb) \\
I' $^{\prime}$ & I, I', II & Verifies parent plant (AABb) \\
I' & II & Parent plant must have been AAbb (II) \\
II & I, I', II & Parent plant must have been AABb (I') \\
II & II & Verifies parent plant (AAbb) \\
II & I, I', II, II', III & Verifies parent plant (AaBb) \\
II & I, I', II, II', III & Verifies parent plant (AaBb) \\
II' & I, I', II, II', III & Verifies parent plant (AaBb) \\
II' & II, II', III & Verifies parent plant (Aabb) \\
II' & II, II', III & Verifies parent plant (Aabb) \\
II' & II, II', III & Verifies parent plant (Aabb) \\
& II, II', III & Verifies parent plant (Aabb) \\
\hline
\end{tabular}

as III. However, in the $F_{2}$ of the cross $\mathrm{C}_{1} 39 \times 05-8$ minor segregation was observed within the III phenotype. It appeared that with proper measurements these three genotypes could be distinguished by phenotypic classification.

Progenies from the cross of $\mathrm{C}_{1} 39$ to either I 8-8 or I4-5, which were both scored as II in the $F_{1}$, gave plants ranging from I to III in the $F_{2}$.

Thus, all of the information from the $196 \mathrm{I}$ study supported the two-locus model. There was, however, some misclassification of individual plants in the previous generation. At this time, the four homozygous classes for a two-factor model had been established as I 8-8 (AABB), Hicks (AAbb), Gi 39 (aaBB) and 05-8 (aabb).

The remainder of the paper will be devoted to details of verification of the two-locus model and to measurement criteria to distinguish among genotypes.

\section{MATERIALS AND METHODS}

The nine possible genotypes for a two-locus model were obtained by selfing and intercrossing the two original parents, Hicks and $\mathrm{C}_{1} 39$, and the recovered homozygous genotypes, 18-8 and 05-8. No attention was given to which homozygote 
was used as the male or female parent, since in a previous study by Matzinger, Mann and Cockerham (1962) no reciprocal differences were noted for all possible crosses among eight varieties for a series of characters. However, the cross of Hicks $\times \mathrm{C}_{1} 39$ was not included in that study.

The experiments were conducted at Whiteville, and Rocky Mount, N.C., in 1962. At each location four replications of a randomised block design were used. Each block consisted of 9 plots with I 5 competitive plants per plot. All plants were topped immediately below the first floral branch of the inflorescence. All other cultural practices were those that are generally used for the production of flue-cured tobacco.

Data concerning leaf shape were collected in the following manner. On each plant every third leaf beginning with the top leaf of the plant was selected. Even though the leaves were selected by counting from the top they were removed from the plants as they matured, beginning at the bottom of the plant.

Seven measurements on the left side of the abaxial leaf surface were taken. All linear measurements were recorded in centimetres $(\mathrm{cm}$.) and angular measurements in degrees. They were:

tip width: leaf width at a point two lateral veins from the leaf tip,

middle width: leaf width at the widest section of the leaf,

base width: leaf width at a point two lateral veins from the sinus,

tip angle, middle angle, base angle: angles of the lateral veins with respect to the midrib taken at the same positions as the leaf width measurements, and

vein number: the number of lateral veins from the sinus to the tip of the leaf on one side of the midrib.

In the analyses of variance all sources of variation were considered random except genotypes. Using an orthogonal set of polynomials (Steel and Torrie, 1960) the eight degrees of freedom for genotypes were partitioned into the following sources of variation where linear and quadratic terminology is equivalent to additive and dominance genetic terminology (Cockerham, I954):

$$
\begin{aligned}
& \mathrm{A}_{l}=\text { additive effect of the } \mathrm{A} \text { locus } \\
& \mathrm{B}_{l}=\text { additive effect of the } \mathrm{B} \text { locus } \\
& \mathrm{A}_{a}=\text { dominance effect of the } \mathrm{A} \text { locus } \\
& \mathrm{B}_{a}=\text { dominance effect of the } \mathrm{B} \text { locus } \\
& \mathrm{A}_{l} \mathrm{~B}_{l}=\text { additive effect of } \mathrm{A} \times \text { additive effect of } \mathrm{B} \\
& \mathrm{A}_{l} \mathrm{~B}_{q}=\text { additive effect of } \mathrm{A} \times \text { dominance effect of } \mathrm{B} \\
& \mathrm{A}_{q} \mathrm{~B}_{l}=\text { dominance effect of } \mathrm{A} \times \text { additive effect of } \mathrm{B} \\
& \mathrm{A}_{a} \mathrm{~B}_{a}=\text { dominance effect of } \mathrm{A} \times \text { dominance effect of } \mathrm{B} .
\end{aligned}
$$

Discriminant analysis. Since it would be helpful to know if certain of the leaf characters could be used either by themselves or compositely to determine the different genotypes a discriminant analysis was used. The discriminant function is defined as $y=\sum_{i=1}^{c} \lambda_{i} x_{i}$ where $x_{i}$ is the $i$ th character measured, $c$ is the number of characters and $\lambda_{i}$ is the coefficient to be estimated of the $i$ th character. Then the sum of squares of

$$
\begin{aligned}
y=\operatorname{SS}(y)=\lambda_{1}^{2} \operatorname{SS} x_{1}+ & \lambda_{2}^{2} \operatorname{SS} x_{2} \\
& +\ldots+\lambda_{c}^{2} \operatorname{SS} x_{c} \\
& +2 \lambda_{1} \lambda_{2} \operatorname{SCP}\left(x_{1}, x_{2}\right)+\ldots+2 \lambda_{c-1} \lambda_{c} \operatorname{SCP}\left(x_{c-1}, x_{c}\right) .
\end{aligned}
$$

If $b_{i j}$ and $e_{i j}$ are the sums of squares among and within genotypes of character $x_{i}$, respectively, $i=j$, and if $b_{i j}$ and $e_{i j}$ are the corresponding sums of cross products of 
characters $x_{i}$ and $x_{j}, i \neq j$, then the sums of squares of $y$ among and within genotypes are

and

$$
b=\sum_{i, j=1}^{c} \lambda_{i} \lambda_{j} b_{i j}
$$

$$
e=\sum_{i, j=1}^{c} \lambda_{i} \lambda_{j} e_{i j}
$$

The degrees of freedom for $b$ and $e$ are $n_{1}$ and $n_{2}$, respectively.

The best discriminant maximises the difference among genotypes and so maximises the ratio, $r=b / e$. This maximum is found by equating to zero the first derivatives of $r$ with respect to each $\lambda_{i}$. The solution in matrix notation is $[\mathrm{B}-r \mathrm{E}] \lambda$ $=0$, where $B$ is the matrix of sums of squares and cross-products among genotypes, $\mathrm{E}$ is the similar matrix for error, and $\partial$ is the column vector of the required discriminant coefficients, $\lambda_{i}$. The preceding equation can be rewritten as

$$
\left[\mathrm{E}^{-1} \mathrm{~B}-r \mathrm{I}\right] \lambda=0 \quad \text { or } \quad \mathrm{E}^{-1} \mathrm{~B} \lambda=r \lambda .
$$

For non-trivial solutions of $\partial$ the determinant $\left|\mathrm{E}^{-1} \mathrm{~B}-r \mathrm{I}\right|$ must be zero. The determinant vanishes for $c$ values of $r$ (mathematically the characteristic roots of

TABLE 3

Analysis of variance of $\mathrm{y}$ in terms of the maximum root $\mathrm{r}$

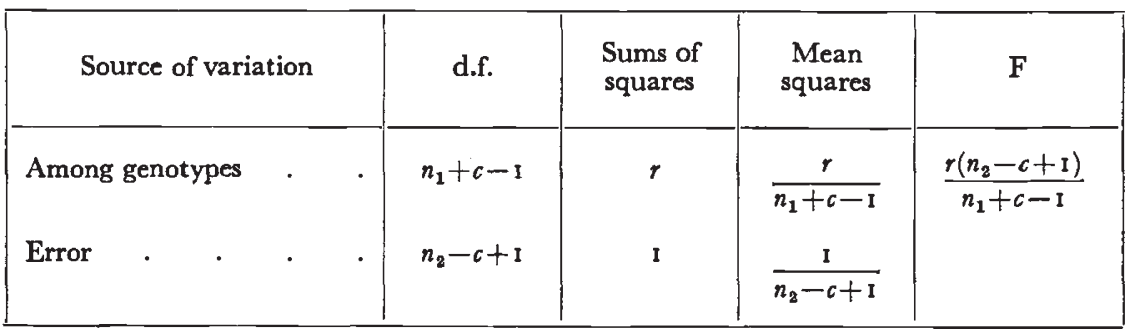

TABLE 4

Analysis of variance of $\mathrm{y}$ in terms of deviations from the mean

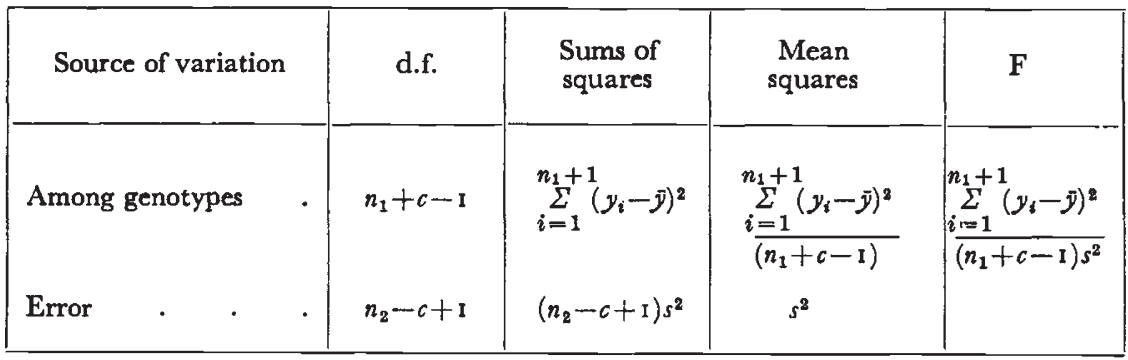

$\left.\mathrm{E}^{-1} \mathrm{~B}\right)$ of which the maximum positive value is required in the present context (Rao, 1952). Once this maximum root is obtained it can be substituted back into $[\mathrm{B}-r \mathrm{E}] \lambda=\mathrm{o}$ to solve for $\lambda$. This furnishes the discriminant function except for an arbitrary constant factor. Fisher's (1948) approach differs in that he solved the equations $[\mathrm{B}-\theta \mathrm{T}] d=0$, where $\mathrm{T}=\mathrm{B}+\mathrm{E}$. Thus $r=\frac{\theta}{\mathrm{I}-\theta}$ and since the maximum root for $r$ is equal to the maximum root for $\theta$ the two methods are equivalent. 
The significance of the discriminant function in distinguishing among the genotypes is tested by Fisher's (1948, p. 295) analysis of variance of $y$, coded in terms of $r$ instead of $\theta$, as in table 3. The degrees of freedom for among genotypes must be increased by the number $(c-1)$ of independent coefficients fitted and the degrees of freedom for error equally reduced. This is only an approximation of the F statistic but for this purpose it is sufficient.

The detailed pattern of discrimination among genotypes is revealed by the values of $y$ at each genotype. Let $\mathrm{G}$ by the $\left(n_{1}+1\right) \times c$ matrix of the estimated mean values of the $c$ characters for each of the $\left(n_{1}+1\right)$ genotypes. Then $y=G d$ is the column vector of estimated values of the discriminant function for each genotype. A standard error for the values of $y$ is obtained by comparing the actual analysis of variance of $y$ with the coded analysis in table 4. In table 4 the sums of squares of $y$ among genotypes is $\sum_{i=1}^{n_{1}+1}\left(y_{i}-\bar{y}\right)^{2}$ and the error sum of squares is $\left(n_{2}-c+1\right) s^{2}$, where $s$ is the standard error of $y_{i}$. Since the $F$ ratios in tables 3 and 4 must be identical,

and

$$
\begin{gathered}
\frac{\sum_{i=1}^{n_{1}+1}\left(y_{i}-y\right)^{2}}{\left(n_{1}+c-\mathrm{I}\right) s^{2}}=\frac{\left(n_{2}-c+\mathrm{I}\right) r}{\left(n_{1}+c-\mathrm{I}\right)} \\
s^{2}=\frac{\sum_{i=1}^{n_{1}+1}\left(y_{i}-y\right)^{2}}{\left(n_{2}-\varepsilon+1\right) r} .
\end{gathered}
$$

Then $s^{2}$ with $n_{2}-c+1$ degrees of freedom can be used in tests of significance between the estimated values of $y$ for each genotype or to provide a least significant difference between these values.

Tests of significance for the estimated $\lambda_{i}$ cannot be obtained because these coefficients are derived as proportions and not as absolute values. However, Fisher (1948) gives a test of one discriminant function against another which covers many of the cases encountered in practice.

\section{RESULTS}

\section{(i) Analyses of variance}

Each of the seven leaf measurements was analysed in an analysis of variance combined over leaf positions, stalk positions and locations. Two stalk positions selected as giving the maximum range of leaf shape on a plant were the fourth node from the top of the plant (hereafter referred to as the top leaf) and the lowest node on the plant which supported a harvestable leaf. The characters chosen for further analysis were those which had (I) a large genotypic variance ratio, (2) small genotype $\times$ location interaction and (3) small coefficient of variation. These characters were (I) vein number averaged over the top and bottom leaf, (2) average width of the top leaf, (3) average width of the bottom leaf, (4) average vein angle of the top leaf and (5) average vein angle of the bottom leaf (Humphrey, I 963). The means for the width and angle measurements were obtained by averaging over the three leaf positions.

A portion of the analyses of variance, with the orthogonal separation of the variation according to genotypic effects, is given in table 5 for these characters. Additive effects of the $A$ and B loci contributed 
significantly to the overall genotypic variance for all characters while only two cases of dominance and one of epistasis were detected. There was more variation detected at the top of the plant than at the bottom

TABLE 5

Mean squares from a portion of the analyses of variance of plot means for leaf width, angle of venation and vein number, combined over locations

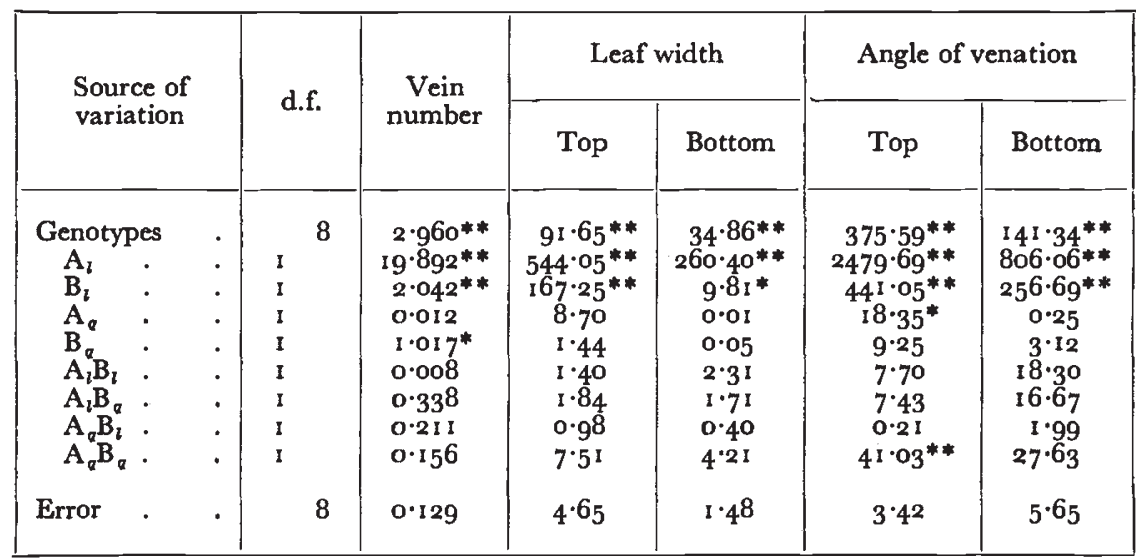

* Significant at 5 per cent. level.

* Significant at I per cent. level.

for both leaf width and angle of venation. However, there was a larger error variance for leaf width at the top of the plant while the converse was found to be true for angle of venation.

TABLE 6

Phenotypic values for vein number

\begin{tabular}{|c|c|c|c|c|c|}
\hline & & BB & $\mathrm{Bb}$ & bb & Mean \\
\hline $\begin{array}{l}\mathrm{AA} \\
\mathrm{Aa} . \\
\mathrm{aa} .\end{array}$ & $\begin{array}{l}\cdot \\
.\end{array}$ & $\begin{array}{l}9 \cdot 80 \\
9 \cdot 44 \\
8 \cdot 60\end{array}$ & $\begin{array}{r}10 \cdot 12 \\
9 \cdot 25 \\
8 \cdot 60\end{array}$ & $\begin{array}{l}9 \cdot 45 \\
8 \cdot 84 \\
8 \cdot 31\end{array}$ & $\begin{array}{l}9 \cdot 79 \\
9 \cdot 18 \\
8 \cdot 50\end{array}$ \\
\hline Mean & . & $9 \cdot 28$ & $9 \cdot 32$ & $8 \cdot 87$ & \\
\hline
\end{tabular}

Among genotype comparisons:

L.S.D. $(0.05)=0.33$
L.S.D. $(0.01)=0.60$

Among marginal comparisons within a given locus:

L.S.D. $(0 \cdot 05)=0 \cdot 19$

L.S.D. $(0.01)=0.35$

The $3 \times 3$ tables of phenotypic values for these five characters (tables 6-ro) show the relative contribution of the genes in various backgrounds. Each value in the body of the tables is the mean of 360 observations except vein number which was obtained from 120 observations. 
TABLE 7

Phenotypic values for leaf width on the fourth leaf from the top of the plant

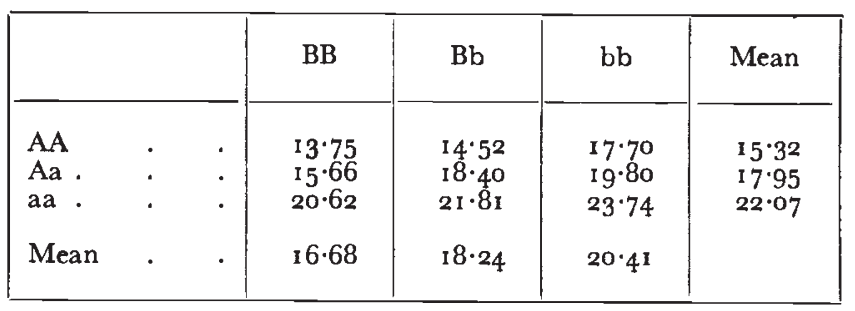

Among genotype comparisons:

L.S.D. $(0 \cdot 05)=2 \cdot 00$
L.S.D. $(0 \cdot 01)=3 \cdot 02$

Among marginal comparisons within a given locus:

L.S.D. $(0 \cdot 05)=1 \cdot 15$

L.S.D. $(0.01)=2 \cdot 09$

\section{TABLE 8}

Phenotypic values for leaf width on the bottom leaf of the plant

\begin{tabular}{|c|c|c|c|c|c|}
\hline & & $\mathrm{BB}$ & $\mathrm{Bb}$ & $\mathrm{bb}$ & Mean \\
\hline $\mathrm{AA}$ & . & $25 \cdot 81$ & $27 \cdot 29$ & $27 \cdot 12$ & $26 \cdot 74$ \\
\hline $\mathrm{Aa}$ & . & $28 \cdot 69$ & $28 \cdot 60$ & $29 \cdot 85$ & 29.05 \\
\hline aa & . & $3^{1 \cdot 28}$ & $31 \cdot 4 \mathrm{I}$ & $3^{1} \cdot 5^{I}$ & $3 \mathrm{I} \cdot 4 \mathrm{O}$ \\
\hline Mean & . & $28 \cdot 59$ & $29 \cdot 10$ & 29.49 & \\
\hline
\end{tabular}

Among genotype comparisons:

L.S.D. $(0 \cdot 05)=1 \cdot 13$

L.S.D. $(0 \cdot 0 \mathrm{I})=2 \cdot 04$.

Among marginal comparisons within a given locus:

L.S.D. $(0 \cdot 05)=0.65$

L.S.D. $(0 \cdot 01)=1 \cdot 18$

\section{TABLE 9}

Phenotypic values for angle of venation on the fourth leaf from the top of the plant

\begin{tabular}{|c|c|c|c|c|c|c|}
\hline & & & $\mathrm{BB}$ & $\mathrm{Bb}$ & $\mathrm{bb}$ & Mean \\
\hline $\mathrm{AA}$ & . & . & $4 I \cdot 8 I$ & $44 \cdot 18$ & $4^{8 \cdot 95}$ & $44 \cdot 98$ \\
\hline $\mathrm{Aa}$. & . & . & $47 \cdot 15$ & $53 . \mathrm{II}$ & 53.02 & $51 \cdot 09$ \\
\hline aa. & . & . & $56 \cdot 6 \mathrm{I}$ & $59 \cdot 66$ & $6 \mathrm{I} \cdot 79$ & $59 \cdot 35$ \\
\hline Mean & • & . & $4^{8 \cdot 52}$ & $52 \cdot 32$ & $54 \cdot 59$ & \\
\hline
\end{tabular}

Among genotype comparisons:

L.S.D. $(0 \cdot 05)=1 \cdot 72$

L.S.D. $(0.01)=3 \cdot 10$

Among marginal comparisons within a given locus:

L.S.D. $(0.05)=0.99$

L.S.D. $(0.0 \mathrm{I})=\mathrm{I} \cdot 79$ 
An additive model with dominance of the $B$ locus fits the data for vein number. The aabb genotype had the fewest veins, with a general tendency of additional veins when progressing toward the AABB genotype. Leaf width values conform to an additive model with less variation attributable to the $B$ locus at the bottom of the plant than at the top. Genotype aabb possessed the widest leaves with a linear trend to the $\mathrm{AABB}$ genotype with the narrowest leaves. Angle of

TABLE 10

Phenotypic values for angle of venation of the bottom leaf of the plant

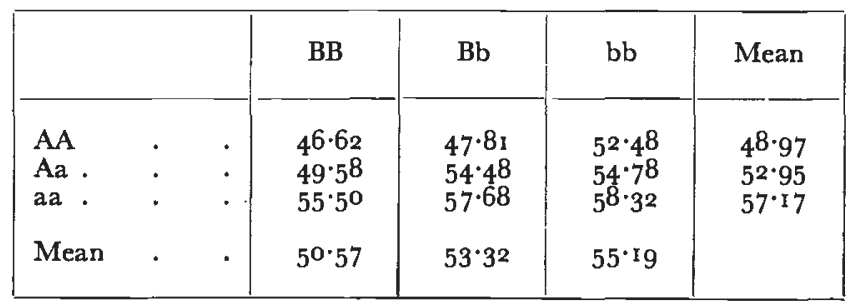

Among genotype comparisons:

L.S.D. $(0 \cdot 05)=2 \cdot 21$

L.S.D. $(0 \cdot 01)=3.99$

Among marginal comparisons within a given locus:

L.S.D. $(0 \cdot 05)=1 \cdot 28$

L.S.D. $(0 \cdot 01)=2 \cdot 30$

venation exhibited a tendency toward an epistatic model with dominance at the top of the plant for the A locus. In regard to this character the top of the plant exhibited more variation with the aabb genotype having the most obtuse angle and AABB the most acute.

\section{(ii) Discriminant analysis}

In the present study, locations were considered as random variables so the genotype $\times$ location source of variation was used as error in the $\mathrm{E}$ matrix. From $\mathrm{E}^{-1} \mathrm{~B}$ the maximum root, $r$, was estimated to be $700 \cdot 52$. The resultant vector, $\underline{\lambda}$ was obtained.

$$
\underline{\lambda}=\left[\begin{array}{l}
\text { Veins } \\
\text { Top width } \\
\text { Base width } \\
\text { Top angle } \\
\text { Base angle }
\end{array}\right]=\left[\begin{array}{l}
1 \cdot 00000 \\
0.52045 \\
0.35625 \\
0 \cdot 16596 \\
0.36578
\end{array}\right] .
$$

Multiplying $\underline{\lambda}$ by a matrix, $G$, of grand means for the various characters, values were obtained for each genotype which comprise $y$ (table I I). Using these values and an additive gene model, a regression analysis was computed to determine the relative contribution of the $A$ and $B$ loci. As determined by this analysis the A locus contributed 4.5 and 
TABLE II

Estimated phenotypic values taken from $\mathrm{y}$

\begin{tabular}{|c|c|c|c|c|c|}
\hline & & $\mathrm{AA}$ & $\mathrm{Aa}$ & aa & Mean \\
\hline $\begin{array}{l}\mathrm{BB} \\
\mathrm{Bb}: \\
\mathrm{bb}\end{array}$ & : & $\begin{array}{l}50 \cdot 16 \\
52 \cdot 19 \\
55 \cdot 60\end{array}$ & $\begin{array}{l}53 \cdot 75 \\
57 \cdot 8 \mathrm{I} \\
58 \cdot 56\end{array}$ & $\begin{array}{l}60 \cdot 17 \\
62 \cdot 15 \\
63 \cdot 54\end{array}$ & $\begin{array}{l}54 \cdot 69 \\
57 \cdot 38 \\
59 \cdot 23\end{array}$ \\
\hline Mean & . & $52 \cdot 65$ & $5^{6 \cdot 74}$ & $6 r \cdot 95$ & \\
\hline
\end{tabular}

Among genotype comparisons:

L.S.D. $(0 \cdot 05)=1 \cdot 26$

L.S.D. $(0 \cdot 01)=1 \cdot 80$

the B locus $2 \cdot I$ to the residual effects of 50.5 units. The regression of phenotypic values on the estimated genotypic dosage values is illustrated in fig. I. The discriminant analysis after fitting regression, table 12, shows that regression accounted for the major portion of the variance.

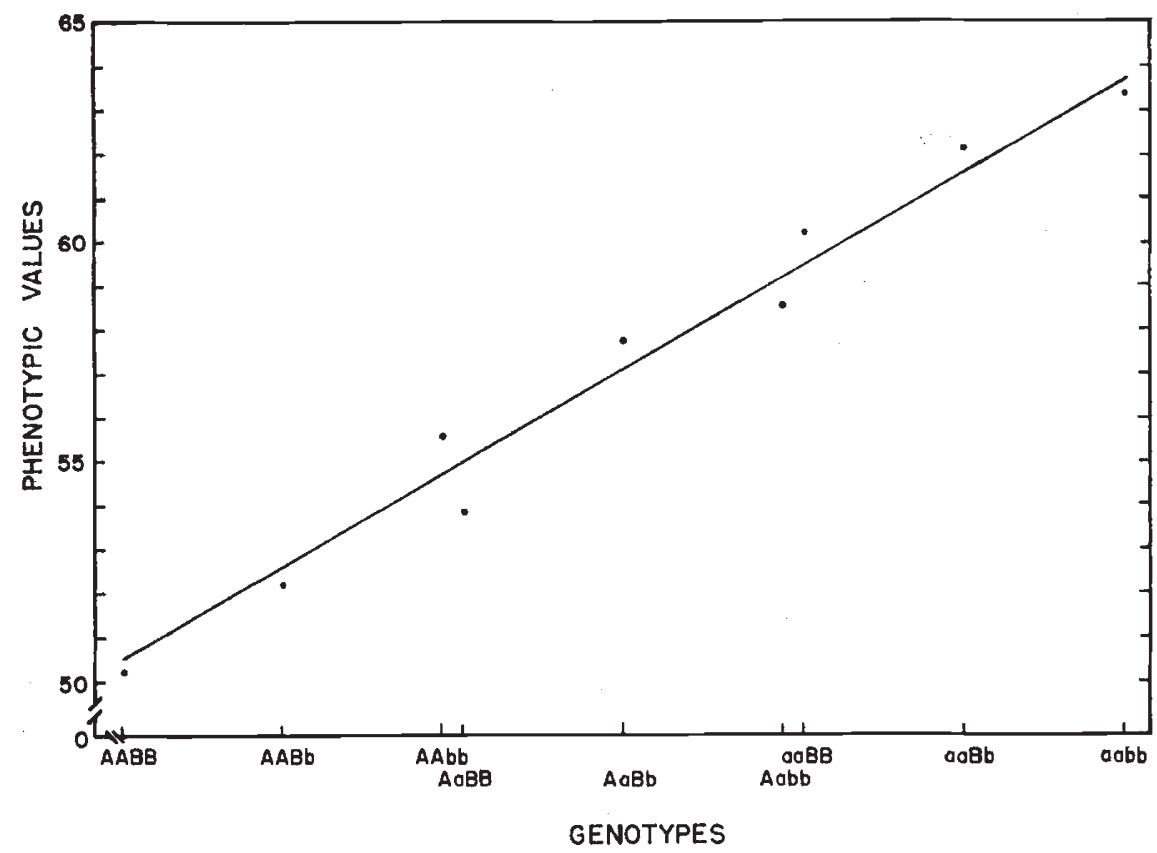

Fig. I.-Regression of phenotypic values, obtained from the discriminant function, against genotypes scaled by estimated gene dosage (see text).

The deviations mean square, although significant, is small in comparison to the regression mean square.

The previously defined $s^{2}$ was used in computing the least significant differences found in table I I. All values in $y$ are significantly different from each other except the values for genotypes $\mathrm{AaBb}\left(\mathrm{F}_{1}\right)$ and $\mathrm{Aabb}$. 
TABLE 12

Discriminant analysis of variance

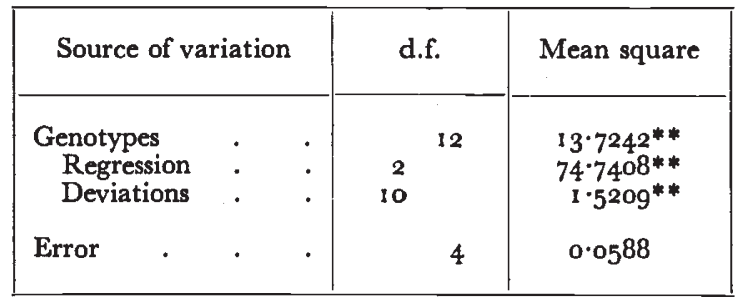

** Significant at I per cent. level.

\section{DISCUSSION}

A few general conclusions can now be made concerning the genetic model for the inheritance of leaf shape in the Hicks $\times \mathrm{C}_{1} 39$ family. These are, (I) the hypothesised genotypes are correct, (2) the A locus has about twice as large an effect on leaf shape as the B locus and (3) the primary gene action is additive. These conclusions are in general agreement with those of Van der Veen (1957) in the cross KE-AM for

TABLE 13

Dosage relationship among genotypes (Arabic numerals) and visual scoring classes (Roman numerals)

\begin{tabular}{|c|l|l|l|}
\hline & $\begin{array}{c}\text { AA } \\
\text { PtPt }\end{array}$ & \multicolumn{1}{c|}{$\begin{array}{c}\text { Aa } \\
\text { Ptpt }\end{array}$} & \multicolumn{1}{c|}{$\begin{array}{c}\text { aa } \\
\text { ptpt }\end{array}$} \\
\cline { 2 - 3 } BB & I & II & III (C. 39) \\
PdPd & 6 & 4 & 2 \\
Bb & I $^{\prime}$ & II (F & III \\
Pdpd & 5 & 3 & 1 \\
bb & II (Hicks) & II' & III \\
pdpd & 4 & 2 & 0 \\
\hline
\end{tabular}

the $\mathrm{Pt}$ and $\mathrm{Pd}$ leaf shape loci described by Glausen and Gameron (1944). The A and B loci in question here are most likely the $\mathrm{Pt}$ and $\mathrm{Pd}$ loci where $\mathrm{A}=\mathrm{Pt}$ and $\mathrm{B}=\mathrm{Pd}$. The genotype for Hicks is then PtPtpdpd and $\mathrm{Cr}_{1} 39$ is ptptPdPd. Crosses of Hicks and $\mathrm{Gr}_{39}$ to $\mathrm{Pt}$ and Pd marker stocks are necessary to confirm this prediction.

The relative dosage effects are very nearly $A=2 B$ in the present material. Van der Veen (personal communication) has also indicated that the dosage relationship between the $\mathrm{Pt}$ and $\mathrm{Pd}$ loci is approximately $\mathrm{Pt}=2 \mathrm{Pd}$. These dosage classes and the visual scoring classes observed in the present study appear in table 13.

There are several differences between the genotypic model derived from the dosage effects and the visual scores. Within Glass II the $F_{1}$ 
should be distinguishable from the other two members of the class. The phenotypic differences are small since by visual scores all three are placed in the same class. On the basis of visual scoring, genotypes $\mathrm{Aabb}$ and $\mathrm{aaBB}$ can be separated though the genetic model does not support this separation. It is possible that the observable difference between these two classes is attributable to differences in the genetic background. It had been impossible to separate the three genotypes in class III visually. From the discriminant function the three genotypes were distinguishable. Apparently, the measurements used are not readily observable to an individual scoring the plants visually.

The practical value of the discriminant function lies in its ability to categorise the genotypes when observations are made on individual $\mathrm{F}_{2}$ plants. The present study indicates that precise classification cannot be attained by this method. The possibility of using flower morphology data in the discriminant function will probably improve this classification. Clausen and Cameron (1944) described differences in flower morphology associated with the Pt factor. Also, East (I9I3) reported floral characters to be relatively stable when observed in different environments. In the present study a few floral characters were measured to suggest those which might be helpful. Although not enough observations were obtained to use them in a discriminant function, corolla tube base, corolla tube length and calyx circumference appeared to help distinguish among the aa-- or ptpt-- genotypes.

The additive nature of the gene effects for the components of leaf shape is in agreement with a general preponderance of additive genetic variance for most characters in segregating populations of flue-cured tobacco (Robinson, Mann and Comstock, 1954; Matzinger, Mann and Robinson, I96o; Matzinger, Mann and Cockerham, i962). Van der Veen (personal communication) has indicated that in a number of crosses which he has studied, there has been a considerable amount of non-additiveness of gene effects. He has assumed that the same major loci are involved in all crosses, but that background modifiers affect phenotypic expression.

From visual observation of other flue-cured tobacco varieties, it would appear that each might be one of three genotypes: AAbb, $\mathrm{aaBB}$, or aabb. Crosses among other varieties and to $\mathrm{Pt}$ and $\mathrm{Pd}$ marker stocks would establish if these loci are determining basic leaf shape and if they are common throughout all varieties.

\section{SUMMARY}

A two-locus hypothesis for the inheritance of leaf shape in the cross Hicks $\times \mathrm{C}_{1} 39$ was postulated on the basis of test crosses. The nine genotypes were grown at two locations with four replications at each location. Various leaf characters were analysed, of which vein number, leaf width and angle of venation were chosen as the characters best able to determine the different genotypes. These characters were 
used in a discriminant analysis to determine whether the discriminant function could be used in separating the nine genotypes into nine separate phenotypic classes. This was almost completely successful when plot means were used for the various genotypes but may be of limited use when individual plant data are used.

The dosage effects of the loci, designated $A$ and $B$, were approximately $2: I$, with little dominance within loci or interaction between loci. It is postulated that these are the Pt and Pd loci in Nicotiana tabacum, however, no tests for allelism with marker stocks were made.

Acknowledgments.- The assistance of Drs B. I. Hayman and C. Clark Cockerham in the statistical procedures is gratefully acknowledged.

\section{REFERENCES}

CLAUSEN, R. E., AND CAMERoN, D. R. 1944. Inheritance in Nicotiana tabacum. XVIII. Monosomic analysis. Genetics, 29, 447-477.

COCKERHAM, C. CLARK. I954. An extension of the concept of partitioning hereditary variance for analysis of covariances among relatives when epistasis is present. Genetics, 39, 859-882.

EAST, E. M. IgI3. Inheritance of flower size in crosses between species of Nicotiana. Bot. Gaz., 55, I 77-1 88.

FISHER, R. A. I950. Statistical Methods for Research Workers. (I I th Edition) Hafner Publishing Co., Inc., New York.

HUMPHREY, A. B. 1963. Inheritance of leaf shape in a cross of two flue-cured tobacco varieties. M.S. Thesis. North Carolina State of U.N.C. Library, Raleigh, North Carolina.

MATZINGER, D. F., MANN, T. J., AND COCKERHAM, G. C. 1962. Diallel crosses in Nicotiana tabacum. Crop Science, 2, 383-386.

MATZINGER, D. F., MANN, T. J., AND ROBINSON, H. F. 196o. Genetic variability in flue-cured varieties of Nicotiana tabacum. I. Hicks Broadleaf $\times$ Coker 139 . Agron Jour., 52, 8-1 I.

RAO, C. R. 1952. Advanced Statistical Methods in Biometric Research. John Wiley and Sons, Inc., New York.

ROBINSON, H. F., MANN, T. J., AND COMSTOCK, R. E. I954. An analysis of quantitative variability in Nicotiana tabacum. Heredity, 8, 365-376.

Steel, R. G. D., AND torrie, J. H.. Ig6o. Principles and Procedures of Statistics. McGrawHill Book Co., Inc., New York.

VAN DER VEEN, J. H. 1957. Studies on the inheritance of leaf shape in Nicotiana tabacum L. Excelsior, Oranjeplein, The Hague.

VAN DER VEen, J. H., AND BINK, J. P. M. I $196 \mathrm{r}$. Multiple effects of the leaf shape allele $\mathrm{Pt}$ in Nicotiana tabacum L. Genetica, 32, 33-50. 